\title{
МАКРОЭКОНОМИЧЕСКИЙ АНАЛИЗ НАЦИОНАЛЬНОГО БОГАТСТВА РОССИИ И ЕГО ЭЛЕМЕНТОВ
}

\author{
(c) 2020 Афонасьев Максим Альбертович \\ аспирант \\ Самарский государственный экономический университет, Россия, Самара
}

(c) 2020 Афонин Сергей Евгеньевич

Самарский государственный экономический университет, Россия, Самара

В статье проводится анализ макроэкономических показателей национального богатства Российской Федерации как базового показателя источника экономического развития и благосостояния. В ходе анализа оценивается состав и структура национального богатства, в том числе: составляющие, которые отражают результат инвестиционной деятельности в экономике; природные ресурсы; финансовая составляющая, которая определяет способность национальной экономики к воспроизводству и наращению экономического потенциала. При этом также уделено внимание особенностям методологии определения изучаемых показателей в рамках современной практики национального счетоводства. Сделаны выводы о характере формирования активов российской экономики. В заключении предлагается общая макроэкономическая оценка эффективности использования национального богатства как основы экономического потенциала и источника экономического роста.

Ключевые слова: национальное богатство, экономический актив, накопление основного капитала, счет операций с капитала, баланс активов и пассивов, воспроизводство капитала.

\section{Введение.}

Современная система макроэкономических показателей представляет собой ряд величин, охватывающих разные стадии производственного процесса в национальной экономике, показатели его результатов и потенциала, который формируется и аккумулируется по итогам текущего воспроизводственного периода. К последним можно отнести величину национального богатства как накопленный результат функционирования национальной экономики, а также источник ее экономического потенциала и роста.

Обращаясь к проблематике исследования национального богатства России в целом и его элементов в отдельности, мы находим достаточное количество публикаций в открытой научной литературе. Так в качестве авторов, рассматривающих широкий спектр вопросов от изучения динамики воспроизводимого капитала, до влияния национально богатства на эффективность экономики, можно назвать следующих: Бакиева Д. М. [4], Дасковский В.Б. [5], Латушко Н.А. [6], Лимонова Н. Г. [7], Никоненко В. А. [8], Цыпин А. П. [9], Хананов М.Р. [10]. Опираясь на опыт указанных авторов, подробно остановимся на аспектах макроэкономического анализа рассматриваемой категории, таких как оценка ее развития и использования экономикой.

\section{Методы исследования.}

Согласно официальному определению в рамках методологии формирования макроэкономических показателей «национальное богатство представляет совокупную стоимость всех экономических активов (нефинансовых и финансовых), находящихся на ту или иную дату в собственности резидентов данной страны, за вычетом их финансовых обязательств, как резидентам, так и нерезидентам» [1].

Важность данного показателя не подвергается сомнению, так как с одной стороны, его величина отражает успешность усилий национальной экономики. С другой стороны, национальное богатство само по себе является отражением возможностей ее дальнейшего развития.

В этой связи возникает вопрос использования данного показателя в качестве одной из базовых величин уровня экономического развития, наряду с валовым внутренним продуктом, среднедушевыми доходами и т.д.

В качестве попытки реализовать данное предложение рассмотрим размеры ВВП и национального богатства России на душу населения и сравним их динамику (рис. 1).

Как видно из рисунка, результат производства в экономике и наращение источника ее экономического потенциала имеют схожую динамику. Этим фактом подтверждается обо- 


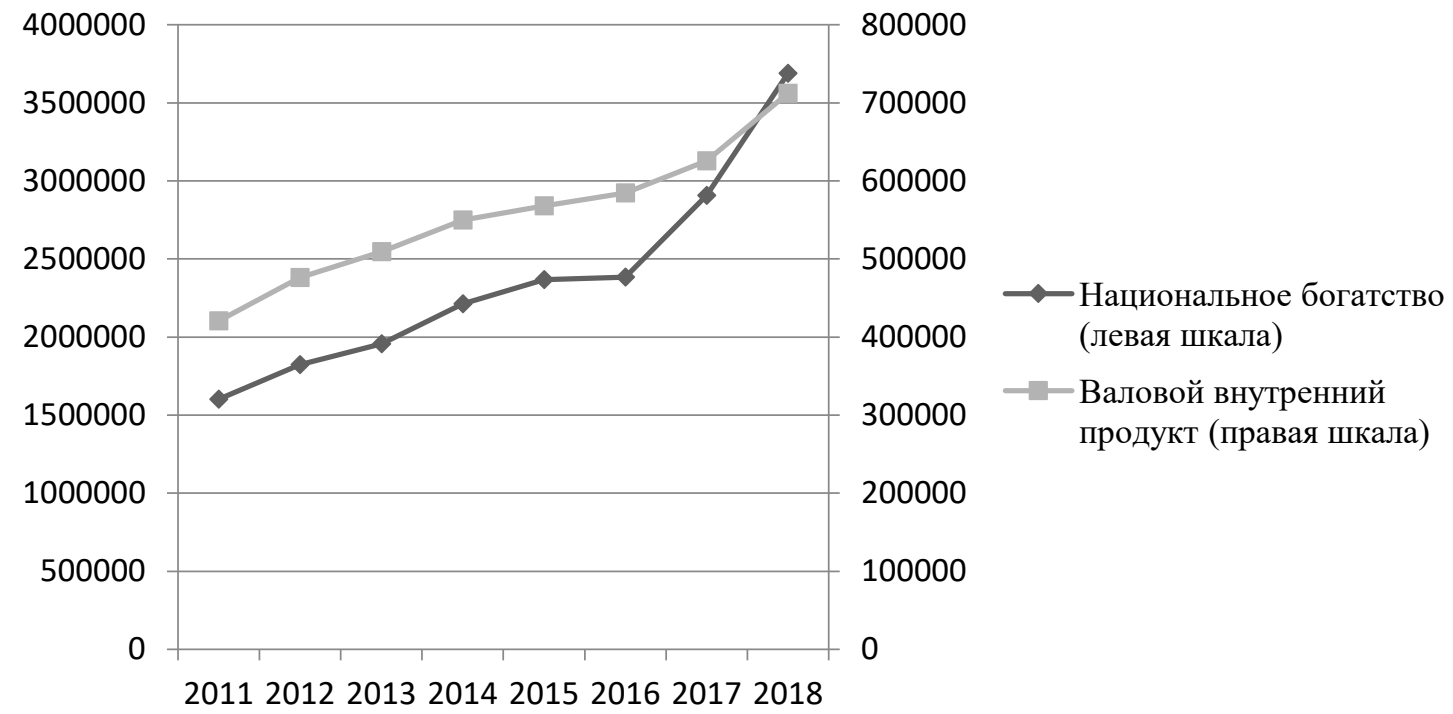

Рисунок 1. Сравнительное изменение подушевых величин национального богатства и ВВП в текущих ценах (2011-2018 гг.)

Источник: составлено автором на основе [1].

снованность использования величины национального богатства как ключевого индикатора уровня экономического развития.

Однако, национальное богатство является более сложной и неоднозначной экономической категорией, чем, например, Валовой внутренний продукт выражающий объем производства всех товаров и услуг национальной экономики. Исходя из определения, данного нами выше, национальное богатство формируется в результате разных процессов: производства, сбережения, накопления, инвестирования, а также привлечения заемных источников. На рисунке 2 укруп- ненно представлены две группы этих разнонаправленных процессов и результат их сочетания, который и дает величину национального богатства.

Таким образом, очевидно, что одним из обязательных вопросов макроэкономического анализа является оценка соотношения величин источников формирования национального богатства. Результаты такого соотношения изображены на рисунке 3.

Как видно из графика на рисунке 3, исходя из сущности категории национального богатства, наращение объема экономических активов

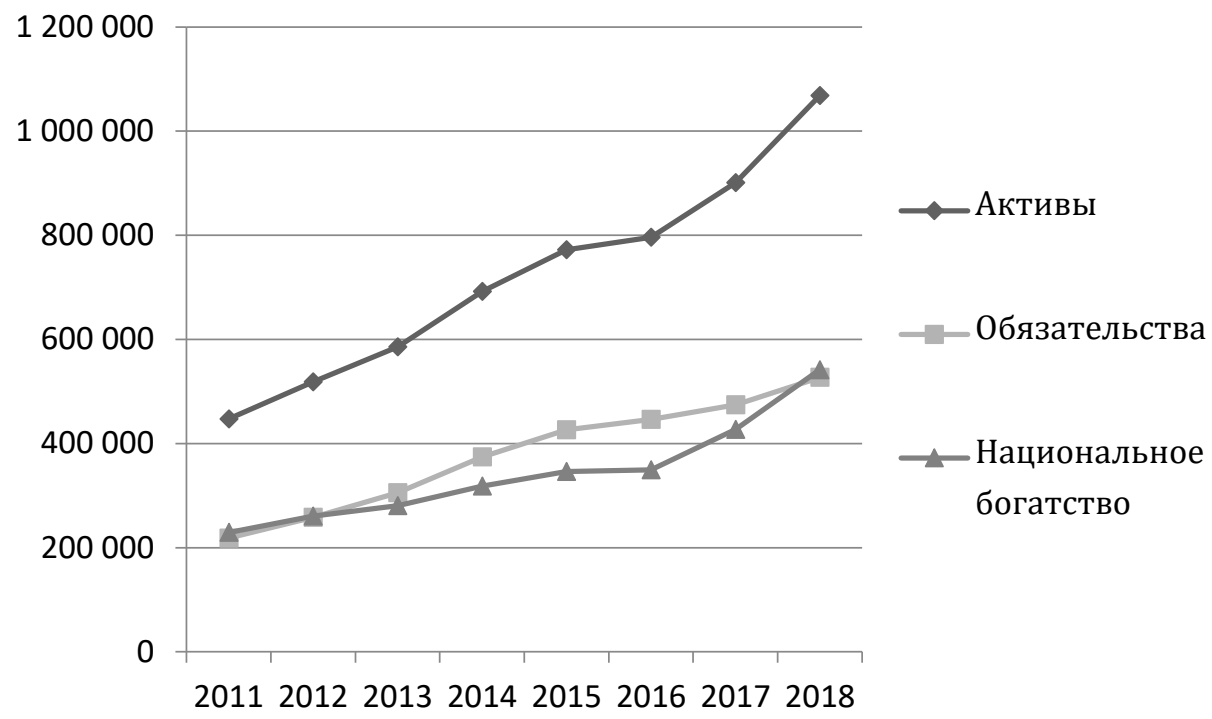

Рисунок 2. Динамика размера национального богатства и источников его формирования в 2011-2018 гг., в текущих ценах, млрд. руб. Источник: составлено автором на основе [1] 


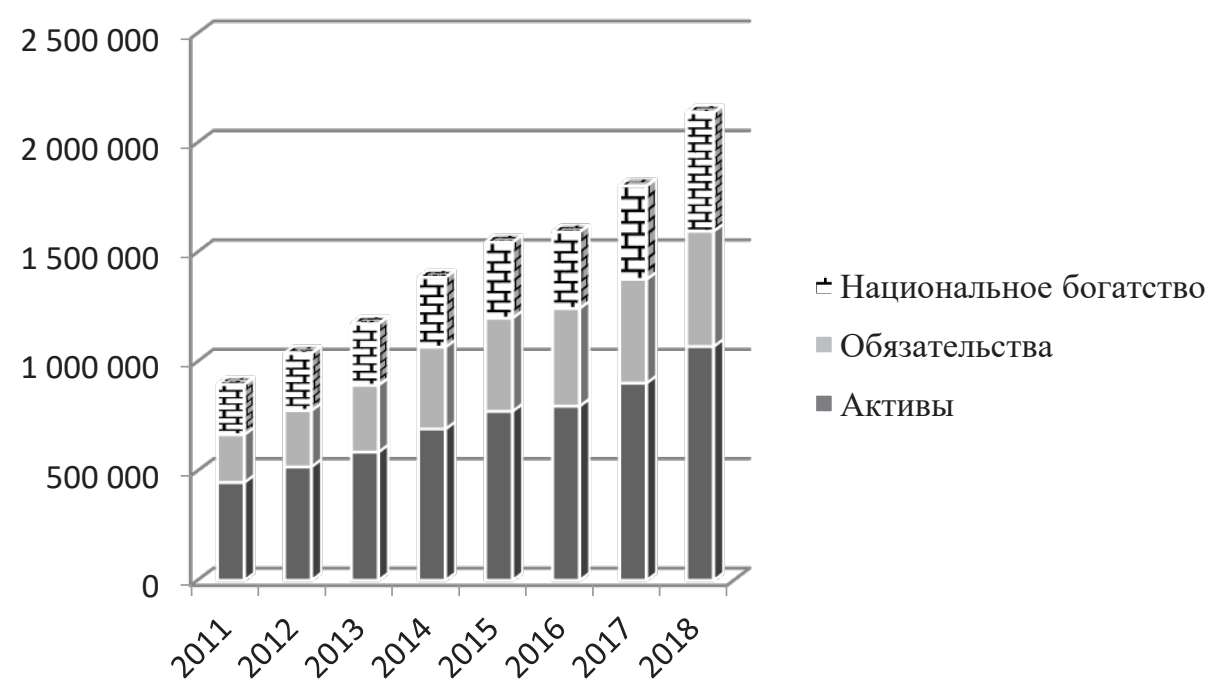

Рисунок 3. Роль стоимости активов и обязательств в формировании размера национального богатства в 2011-2018 гг., в текущих ценах, млрд. руб. Источник: составлено автором на основе [1]

само по себе еще не обеспечивает рост экономического потенциала. Важны также источники этого наращения - обеспечение данного процесса за счет результатов экономического производства национальной экономики. Данный момент можно отследить, например, оценивая соотношение объема активов и обязательств. На рисунке 4 представлена динамика соотношения этих двух категорий, формирующих объем национального богатства.

Заметное и довольно стремительное снижение данного соотношения с 2011 по 2016 гг. говорит о потере российской экономикой самостоятельности и снижении возможностей формировать материальную базу за счет собствен- ных усилий, а также уменьшении потенциала наращения национального богатства. С 2016 г. наблюдается улучшение ситуации и восстановление, практически, такого же уровня в 2018 г.

Такое изменение экономической ситуации непосредственно сказывается на темпах роста показателя национального богатства (табл. 1).

Следующим важным аспектом формирования национального богатства как источника экономического потенциала и роста является его состав. Перечень компонентов национального богатства - давний предмет дискуссий специалистов в области экономики. Но можно сказать, что в современном понимании сложилось общее видение данной категории. Согласно

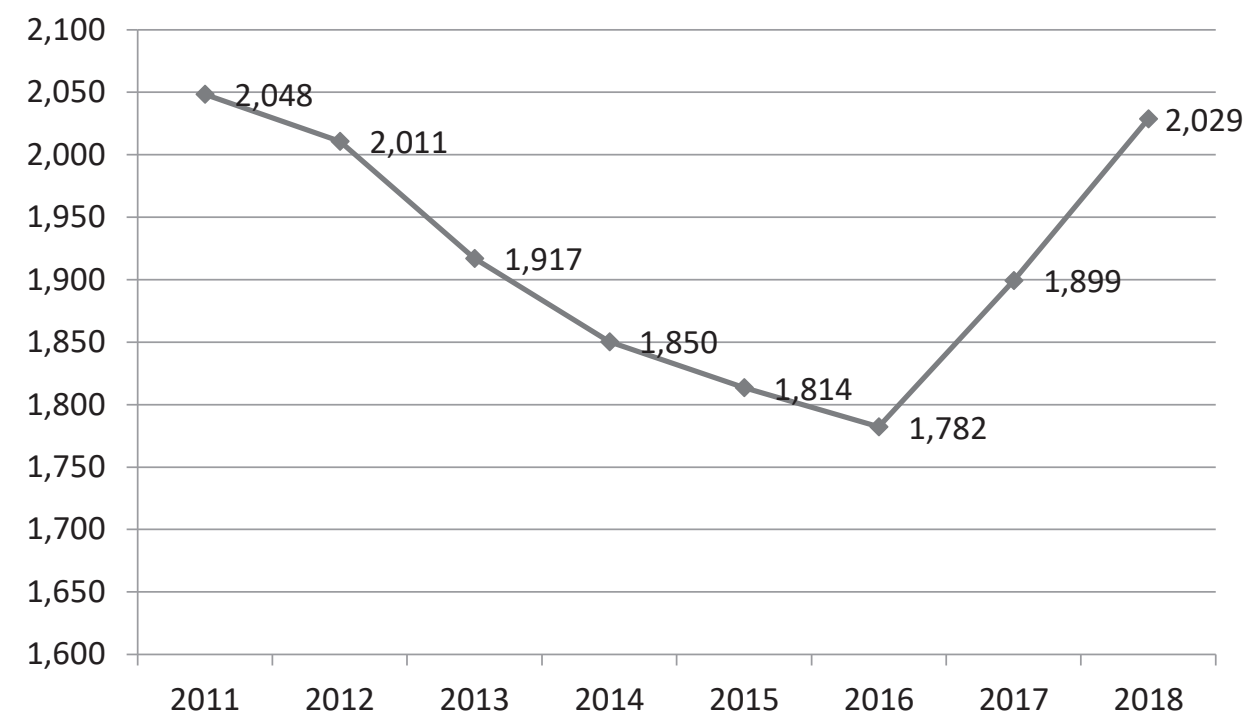

Рисунок 4. Динамика соотношения размера активов и обязательств российской экономики (2011-2018 гг.). Источник: составлено автором на основе [1] 
Таблица 1. Изменение цепных темпов роста национального богатства и источников его формирования

\begin{tabular}{|l|c|c|c|c|c|c|c|c|}
\hline $\begin{array}{l}\text { Темпы роста макроэкономических } \\
\text { показателей, \% }\end{array}$ & 2011 & 2012 & 2013 & 2014 & 2015 & 2016 & 2017 & 2018 \\
\hline Активы & 115,9 & 113,0 & 118,1 & 111,6 & 103,0 & 113,2 & 118,6 & 115,9 \\
\hline Обязательства & 118,1 & 118,5 & 122,3 & 113,9 & 104,8 & 106,2 & 111,0 & 118,1 \\
\hline Национальное богатство & 113,8 & 107,6 & 113,4 & 109,0 & 100,8 & 122,2 & 127,0 & 113,8 \\
\hline
\end{tabular}

ему, в состав национального богатства страны входят следующие компоненты:

- основной капитал;

- финансовые активы;

- природные ресурсы;

- человеческий капитал.

Данный состав является наиболее универсальным из тех, что встречаются в современных исследованиях. Однако в практике формирования макроэкономических показателей имеют место методологические и организационные ограничения, которые влияют на содержание публикуемых и используемых индикаторов.

Так, согласно международной статистической методологии [1] начиная с 1990 г. Росстат оценивает и публикует данные по национальному богатству частично, последовательно совершенствуя и разрабатывая методологию его более детальной оценки. До 2017 г. состав оценки национального богатства включал только информацию о воспроизводимом капитале (основном капитале и финансовых активах). На сегодняшний день нефинансовые активы представлены уже двумя категориями: произведенные активы в виде набора элементов основного капитала и непроизведенные активы, включающие в себя природные ресурсы [1].

Кроме того полнота состава произведенных активов тоже находится в разработке. Так, согласно положениям экономической теории международной статистической методологии туда включаются следующие элементы:

- основной капитал производственного и непроизводственного назначения;

- материальные оборотные средства;

- ценности.

Основной капитал - активы, использующиеся длительный период времени (не менее одного года), предназначенные для следующих целей:

- рыночного и нерыночного производства товаров и услуг;

- управленческих целей;

- платного предоставления во временное пользование другим лицам.
Таким образом, в показателе основного капитала учитывается стоимость зданий и сооружений, машин и оборудования, транспортных средств, культивируемых биологических ресурсов и прочих видов основных фондов организаций.

Материальные оборотные средства представляют собой активы, используемые в краткосрочный период, рамках одного производственного цикла. При этом их отличительной чертой является изменение формы в процессе эксплуатации и переход в новое качество.

Ценности представляют собой произведенные объекты, как правило. Не используемые в процессе производства, а выполняющие функцию запасов с целью сохранения стоимости. В составе данного вида активов учитываются драгоценные камни и металлы и изделия их них, антиквариат, произведения искусства. При этом, в настоящее время не решен вопрос учета в составе ценностей объектов музеев.

На сегодняшний день из вышеперечисленных элементов макроэкономический показатель произведенных активов российской экономики включает в себя все элементы основного капитала и ценности (включены с 2018 г.).

Что касается человеческого капитала, вопрос его оценки и включения в состав макроэкономических показателей до сих пор остается открытым и требует дальнейших научных разработок $[2,3]$.

В качестве примера содержания элементов национального богатства России рассмотрим динамику важнейшего элемента производимых активов - основного капитала (рис. 5).

Учитывая, что анализируемые показатели представлены в текущих ценах, рост стоимости основного капитала за 8 лет не демонстрирует прорывную динамику, способствующую активному технологическому обновлению и модернизации национальной экономики. Общее увеличение материальной базы экономического производства по сравнению с уровнем 2011 г. составило всего 65,5\%. Кроме того структура и состав основного капитала также не отража- 


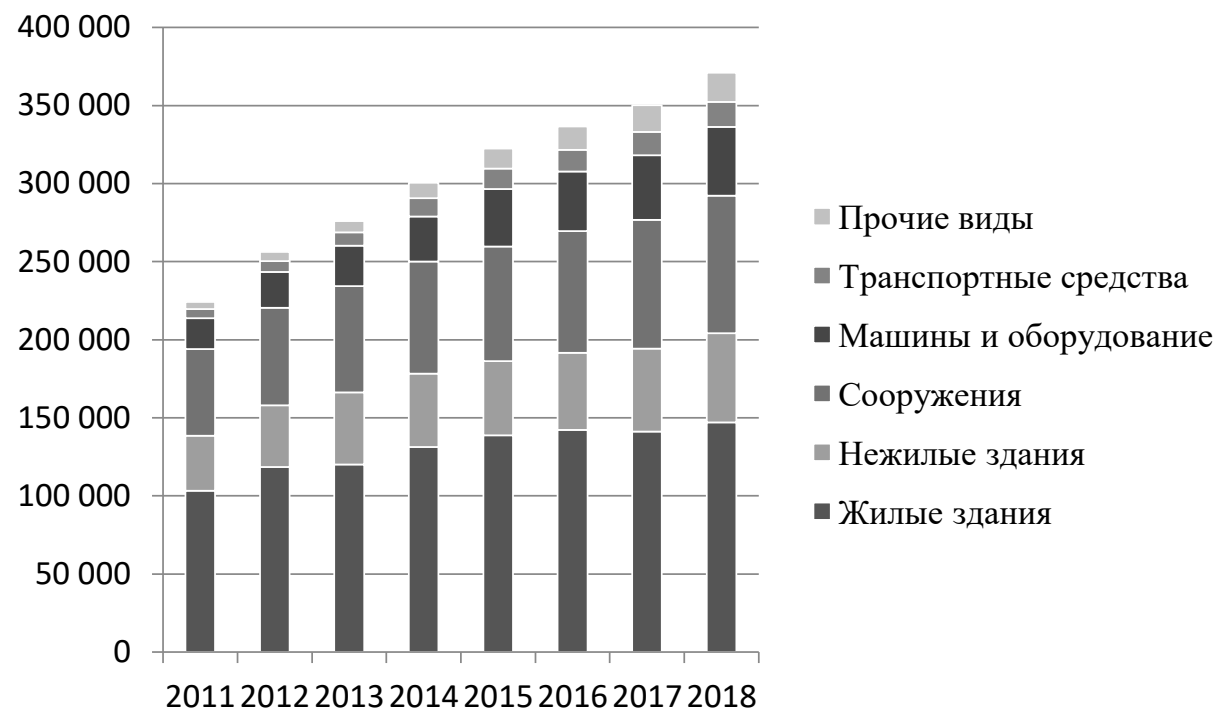

Рисунок 5. Состав и динамика основного капитала российской экономики, млрд. руб. Источник: составлено автором на основе [1]

ет заметных технологических преобразований. бельности активов, используемым на микроуБольшую часть (около 60\%) стоимости основного капитала составляют здания - жилые (более $40 \%)$ и нежилые. Такая структура наблюдается на протяжении всех восьми последних лет.

Тем не менее, в динамике важнейшей части национального богатства наблюдаются положительные тенденции. Не смотря на наличие кризисных периодов в рассматриваемом ряду динамики заметно увеличение наиболее важных для технологического развития и экономического роста составляющих. Существенно увеличилась в составе основного капитала доля машин и оборудования. Средний темп роста данного элемента составил $112,2 \%$ ежегодно на протяжении 2012-2018 гг.; а сам его увеличился в 2,24 раза. Также заметным ростом выделяется такой элемент как транспортные средства, развитие которого является решающим для российской экономики. Прирастая ежегодно в среднем на $15,3 \%$ транспортное обеспечение увеличилось в 2,7 раза по сравнению с уровнем 2011 г.

В заключение, в качестве еще одного направления макроэкономического анализа национального богатства мы предлагаем осуществлять оценку эффективности и отдачи. В качестве обобщающего показателя здесь может выступать соотношение национального богатства и ВВП, по аналогии с показателем рентаровне.

Как видно из таблицы 2, динамика эффективности экономического потенциала российской экономики не имеет тенденцию к росту. Отчасти это можно объяснить некоторым изменением методологии расчета величины национального богатства, при котором произошло добавление некоторых элементов в его состав. И все же, даже усчитывая этот момент, очевидно, что роста эффективности не происходит.

\section{Заключение.}

Результаты проведенного макроэкономического анализа предложенных нами направлений свидетельствуют о безусловном наличии потенциала в российской экономике. Даже не смотря на влияние кризисных периодов, динамика элементов национального богатства демонстрирует рост и восстановление производственного потенциала экономики России в важнейшей его части. Тем не менее, полная реализация потенциальных возможностей не происходит, как показал предложенный нами индикатор эффективности. Данное обстоятельство обусловлено, в том числе, влияние организационных и институциональных факторов, что является отдельным вопросом и предметом научных исследований.

Таблица 2. Динамика относительного показателя эффективности применения элементов национального богатства

\begin{tabular}{|l|c|c|c|c|c|c|c|c|}
\hline Год & 2011 & 2012 & 2013 & 2014 & 2015 & 2016 & 2017 & 2018 \\
\hline $\begin{array}{l}\text { Эффективность применения элементов } \\
\text { национального богатства,\% }\end{array}$ & 26,3 & 26,1 & 26,0 & 24,9 & 24,0 & 24,5 & 21,5 & 19,3 \\
\hline
\end{tabular}




\section{Библиографический список}

1. Национальные счета России [Электронный ресурс] / Росстат.- Режим доступа: https://rosstat.gov.ru/ folder/210/document/13221 (дата обращения: 15.12.2020)

2. Нельсон А. Ю. Современные подходы к оценке человеческого капитала компаний // Вестник научных конференций. 2019. № 10-4 (50). С. 84-86.

3. Измайлова M. О возрастании роли человеческого капитала в экономике знаний // Проблемы теории и практики управления. 2018. № 6. С. 95-105.

4. Бакиева Д.М., Майорова Н. С. Национальное богатство России: структура, динамика, проблемы // Социальные науки. 2019. № 4 (27). С. 10-18.

5. Дасковский В.Б., Киселев В.Б. О принципах стратегии экономического развития России до 2030 г // Экономист. 2017. № 3. С. 24-42.

6. Латушко Н. А. Оценка и измерение структуры национального богатства региона: методические подходы // Российский экономический интернет-журнал. 2018. № 4. С. 67.

7. Лимонова Н.Г. Статистическое моделирование влияния элементов национального богатства на ВРП на основе нейронных сетей // Экономика и предпринимательство. 2013. № 11 (40). С. 376-379.

8. Никоненко В.А. Оценка динамики и эффективности использования национального богатства российской федерации // Международный журнал гуманитарных и естественных наук. 2019. № 12-3 (39). С. $106-109$.

9. Цыпин А.П., Попов В.В. Статистический анализ основных фондов России: наличие, состояние, эффективность использования // Азимут научных исследований: экономика и управление. 2017. Т. 6. № 3 (20). С. $355-358$.

10. Берзон Н. И. Банковский сектор России: вызовы, проблемы и перспективы // Финансы и бизнес. 2016 . № 3. С. 35-46.

11. Хананов М.P., ЛевинаЕ.И. Методы и формы оценки элементов национального богатства // Экономика и социум. 2016. № 1 (20). С. 395-398. 